\section{Ausência de Espaços de Convivio em Gleba Urbana Irregular}

O caso do Loteamento Unochapecó

Segregación social y espacios residuales. Diseño para la colectividad

Social segregation and residual spaces. Design for collectivity

DOI: https://doi.org/10.18861/ania.2021.11.1.3074

\section{Arg. Paula Batistello}

Profesora y Coordinadora del curso de Arquitectura y Urbanismo.

Universidade Comunitária da Região de Chapecó paula.batistello@unochapeco.abea.arq.br

Acadmica del curso de Arquitectura y Urbanismo de Unochapecó

Universidade Comunitária da Região de Chapecó

ORCID: https://orcid.org/0000-0003-3973-7432

Recibido: 16/2/2021

do: $23 / 2 / 202$

Cómo citar: Batistello, P., \& Schuab, A. (2021). Segregación social y espacios residuales: diseño para colectividad. Anales de Investigación en Arquitectura, 11(1). https://doi.org/10.18861/ ania.2021.11.1.3074

Artigo resultado de pesquisa com apoio do Governo do

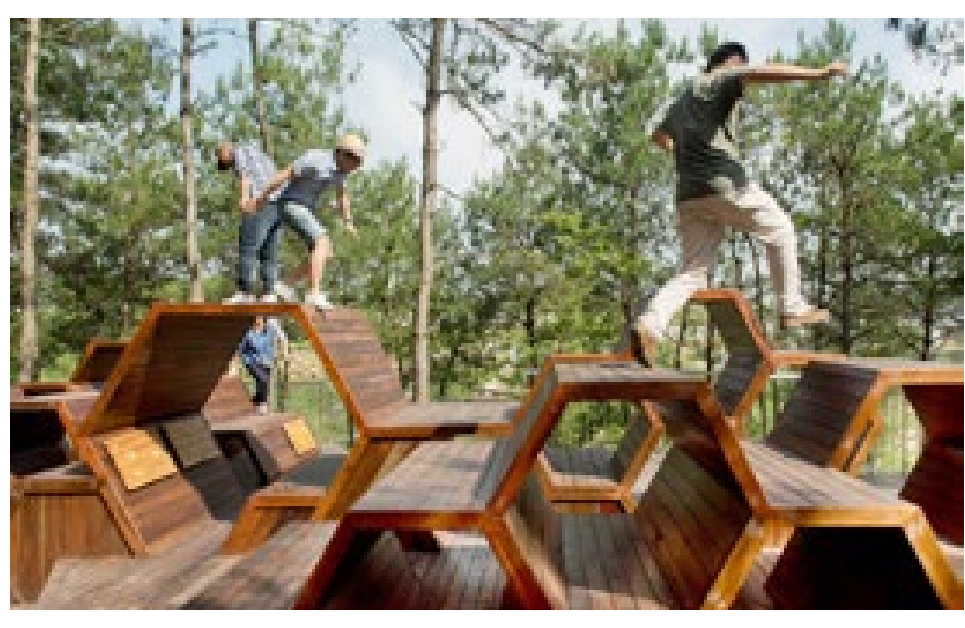

Resumo

Esta pesquisa visa analisar a problemática da configuração de uma gleba urbana ocupada de forma irregular e como a coletividade acontece no local, explorando possibilidades de mobiliários urbanos coletivos para sanar necessidades de convívio e lazer. Tem como objetivo principal relacionar os espaços livres com as possibilidades de methoria da qualidade de vida. Após o envolvimento dos moradores em várias reuniões realizadas com metodologias ativas para compreender as necessidades da população em questão, foi realizada uma consulta local com base nas principais problemáticas apreendidas para observar a compreensão de como o design de mobiliários de uso coletivo pode ser aceito por eles, fora dos padrões tradicionais

Palavras-chave: espaços livres em parcelamento de solo irregulares; mobiliários urbanos; espaços públicos de convivio.
Resumen

Esta investigación tiene como objetivo analizar el problema de la configuración del suelo urbano ocupado irregularmente y como ocurre la colectividad en el luga explorando posibilidades de mobiliario urbano colectivo para resolver las necesidades de socialización y ocio. Su principal objetivo es relacionar los espacios abiertos con las posibilidades de mejorar la calidad de vida. Después de la participación de los vecinos en varios encuentros realizados con metodologías activas para entender las necesidades de la población en cuestión, se realizó una consulta local a partir de los principales problemas aprehendidos para observar la comprensión de cómo se puede aceptar el diseño de mobiliario de uso colectivo. por ellos, fuera de los estándares tradicionales.

Palabras clave: espacios libres en parcelación de tierras irregulares: mobiliario urbano; espacios de vida pública.
Abstract

This research aims to analyze the configuration issue of an irregularly occupied urban gleb and how the collectivity happens in the place, exploring possibilities of collective design to solve the needs of conviviality and leisure. After the involvement of residentes in several meetings held with active metodologies to understand the needs of the population in question, a local consultation was carried out based on the main problems apprehended to observe the understanding of how the design of furniture for collective use can be accepted by them, outside of traditional standards.

eywords: social segregation design for collectivity convivial spaces 


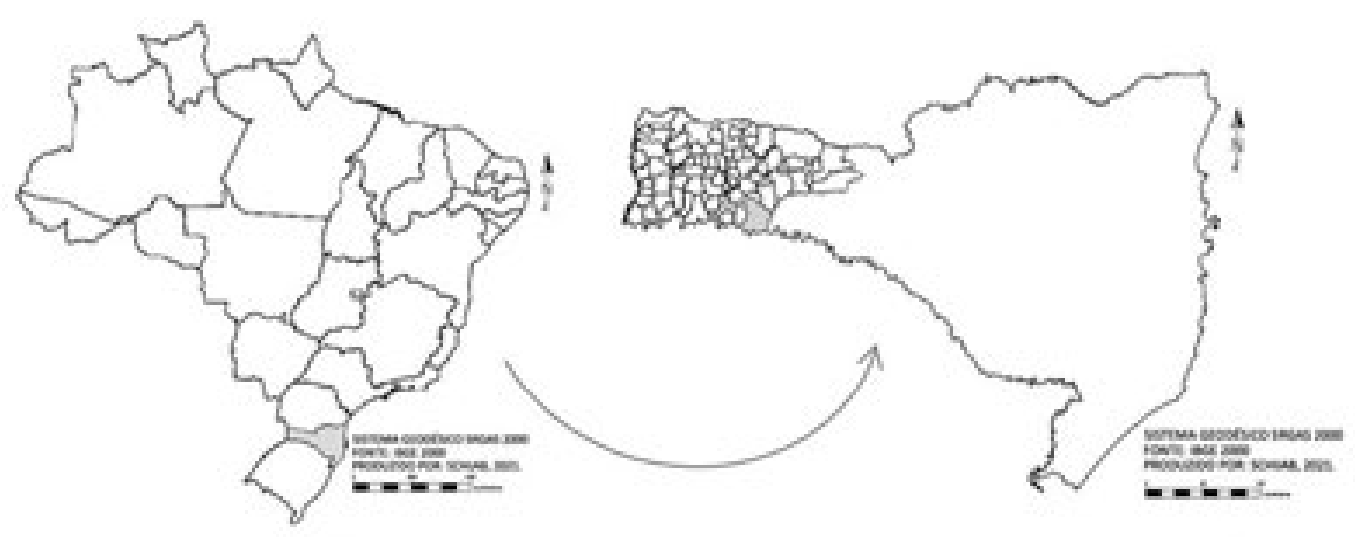

Os espaços em face às áreas que não são alvos de projetos urbanísticos, ou seja, que se formam de forma irregular, embora sejam resultados diretos dos modelos de crescimento urbano, tem seu desenvolvimento de modo limitado. Como ocorrem em sua maioria em espaços residuais, acabam tendo um desenho urbano de lotes pouco acessíveis, com dimensões e formatos irregulares com pequenas ou até ausência de faces conectadas às viss. e por muitas vezes sem áreas permeáveis que permitam o lazer, dentro e fora do lote. Em sua maioria, são espaços que se apresentam fragilizados e decorrem das alterações sucedidas nas dinâmicas econômicas urbanas. Dessa forma, em decorrência do crescente processo
de urbanização, uma série de problemas foram desencadeados, haja vista que as cidades não se encontravam preparadas para acomodar tal massa populacional. Como consequência, parte dos residentes na zona urbana ficaram expostos a condições precárias no que diz respeito à moradia, segurança, saúde e afins, em especial para o proletariado que buscou no crescimento das cidades oportunidade de trabalho, sem condições de acessar moradias em áreas urbanas já estruturadas.

A partir do surgimento de novos centros urbanos, deu-se início a uma nova dinâmica urbano regional, uma vez que dentro desse contexto estão as cidades médias, que atuam como um vínculo entre as pequenas e grandes cidades. Mas, as desigualdades sociais relacionadas à fragmentação e formação do espaço também apresentam consequências negativas para o desenvolvimento social e urbano desses centros. (SILVA et al., 2016. p. 257).

Chapecó, enquanto cidade média, carrega consigo traços desse processo. Localizada na Região Oeste de Santa Catarina (Figura 01), possui uma população estimada pelo Instituto Brasileiro de Geografia Estatística (IBGE) de 224.013 habitantes, e é a maior cidade de uma região composta por 118 municípios onde $75 \%$ destes possuem menos de 10.000 habitantes. Esta região soma 1.302.480 habitantes e transforma Chapecó em um pólo regional. O crescimento populacional e econômico da cidade de Chapecó se deu pela implantação de agroindústrias, e consequentemente a migração de pessoas do campo ou de outras cidades para trabalhar nas mesmas. Em 1952 a cidade inaugurou o Frigorífico Chapecó, e em 1973 a o Frigorífico Sadia, na época em localizações periféricas da cidade. Assim, na década de 70, segundo Reche (2008) há o fortalecimento da figura do loteador clandestino que percebe a necessidade de moradias para esses trabalhadores que buscam constituir suas residências em Por outro lado, a área central se elitiza e iniciamse os marcos de segmentação urbanística.

Em termos de implantação de infraestrutura urbana fez-se importante destacar que, na década de 70 , 0 município participou do programa das obras do Plano "Comunidade Urbana para Renovação Acelerada" (CURA), do Governo Federal. Essa ação estruturou e valorizou consideravelmente alguns bairros de elite (Jardim Itália, Maria Goretti e Santa Maria) em contraposição aos demais. Ainda hoje percebem-se reflexos dessa valorização pelo contínuo investimento em melhorias que neles se verifica (FUJITA, 2008).

Com os investimentos na área central e seus bairros próximos, e a figura do loteador clandestino, inicia-se uma série de ocupações irregulares próximas as indústrias fortes, as agroindústrias. Reche (2008) afirma que se nas décadas de 70 e 80 havia uma expansão territorial da classe de menor renda e isso era importante para a indústria, nos anos 90 e 2000, essas áreas se densificaram aumentando o abismo entre as mais altas rendas que ocupam o centro da cidade, e de mais baixa renda que se mantém nas periferias ao redor das indústrias.
1. Mapa do Brasil com destaque para Santa Crarina (SC). 2. Mapa de SC com destoque para a Regitio Oeste e Chepecó.

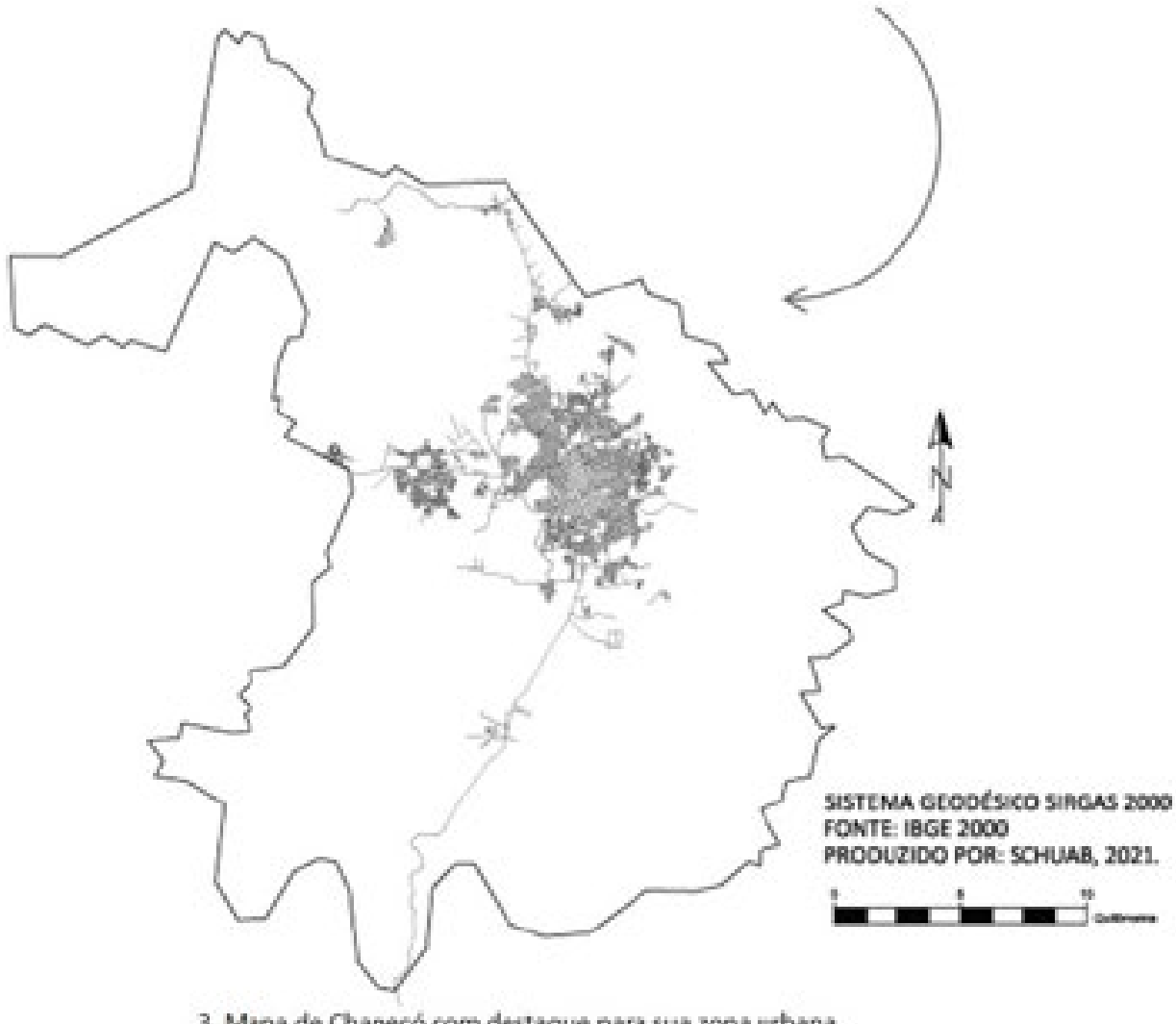

Figura 01: Mapa de localização de Chapecó no Brasil e no Estado de Santa Catarina 
Em cidades como Chapecó, por vezes, a legislação permitiu a inserção de novos loteamentos sem necessariamente haver uma conexão com a malha urbana da cidade desencadeado assim, inúmeras áreas desconexas gerando espaços residuais que, posteriormente, vieram a ser ocupados de forma irregular.

São chamados espaços residuais os "vazios" e as "sobras" de edificações que se acumulam pela cidade como resultado eçoes que se acumulace po de construção resultado do seu contrinaça. São, normalmente, espacialidades sem uso preestabelecido e, por esse motivo, são inconvenientes difíceis de solucionar. Por outro lado, são constantemente apropriados por usuários, uma vez que configuram "disponíveis" para uma infinidade de outros usos que podem surgir na imprevisibilidade do cotidiano. (BALBI, 2007. p. 5)

De acordo com Ferrara (2000), entende-se que é necessarrio "rever o caráter residual do espaço, pois eles se apresentam disponiveis para outras apropriações e novos usos".

É desta forma que nasce o loteamento Unochapecó, nome este dado recentemente em sua regularização no ano de 2012, por conta da proximidade com a Universidade Comunitária da Região de Chapecó - Unochapecó. O loteamento Unochapecó nasceu nos anos 80, segundo contam moradores, de forma irregular, e pela proximidade com o frigorífico Sadia, o que corrobora as informações citadas por Reche (2008), nos parágrafos anteriores.

Com sua constituição irregular, a falta de estrutura urbanística como espaços de lazer e convivio é facilmente notada por quem passa, pois as pessoas acabam ocupando a via para tal. Via esta que será apresentada mais adiante, mas pode-se antecipar que é de grande movimento e estreita para tal. Esta questão ainda foi fortemente abordada pelos moradores em reuniões realizadas no decorrer da pesquisa.

Segundo Vivan e Saboya (2012), as cidades apresentam diferenças na construção de suas estruturas, em consequência às características socioculturais, que geram um desenho urbano que organiza o espaço e os que o habitam. A multiplicidade de usos e a implantação de equipamentos coletivos podem gerar usos mais constantes nos locais pelas pessoas em vários períodos do dia proporcionando mais segurança, por exemplo.

Diante do exposto, sugere-se este estudo para buscar formas de construção de espaços de lazer e convívio que possam ser usufruídos por todos os moradores, independente de idade. A exploração dos espaços residuais com possibilidades uso para convivio e lazer, a partir da exploração dos aspectos levantados pelos moradores do mesmo é uma hipótese para a melhoria da qualidade de vida. Para isso, faz-se necessário discutir alguns conceitos de espaços públicos e seus usos, antecedendo a discussão do objeto em questão.

Espaços públicos urbanos

Os espaços públicos são definidos geralmente como espaços abertos de uso comum, os quais podem ser utilizados livremente pelos habitantes de uma cidade.

Para Yang (2013), espaço público é um espaço amplo onde você favorece o convívio. Já Caracas (2002) afirma que as edificações que compõe as atividades do meio urbano formam as estruturas urbanas, porém define melhor o que são os espaços livres e sugere funções a eles que possam incentivar o convívio social:
Já os espaços livres, no contexto da estrutura urbana, referem-se às "... áreas parcialmente edificadas, com nula ou mínima proporção de elementos construídos e/ou de vegetação - avenidas, ruas, passeios, vielas, pátios, largos, etc. - ou com a presença efetiva de vegetação parques, praças, jardins, etc.". São também considerados espaços livres as áreas com vegetação existente nos quintais, nas áreas de condomínio fechado; as praias e as áreas remanescentes de ecossistemas primitivos como matas, manguezais, etc. Enfim, os espaços livres podem ser não só espaços de circulação e distribuição de infraestruturas e serviços públicos em geral, mas também espaços que atendam às funções de equilíbrio ambiental, à recreação, ao convívio social e composição paisagística. (CARACAS, 2002. P. 03) 
Segundo Francis (1991), a maneira como as pessoas percebem os espaços está diretamente relacionada com 0 uso que elas fazem desses locais.

Os espaços livres urbanos são sentidos de diferentes formas de um indivíduo para outro, pois carregam consigo sentimentos. Dessa forma, estes espaços passam a ter um significado para seus cidadãos, ampliando a ideia de umpaçofísico por sisó. Estes espaços devem ainda idera de espaço físico por si so. Estes espaços devem ainda ter como finalidade, satisfazer as necessidades de seus usuários - o e descanso e proporcionar ao usuário segurança e bem e descanso e proporcionar ao usuário segurança e bem-
estar - visando tornar seu uso mais efetivo, onde deve estar - visando tornar seu uso mais efetivo, onde deve espaços no contexto moderno da cidade.

Principalmente a partir da segunda metade do século $X X$, presenciamos no Brasil um crescimento muito veloz de nossas cidades. Como consequência desse processo de urbanização acelerado, tal expansão gerou uma segregação socioespacial cada vez maior, que levou a classe trabalhadora para regiões periféricas, e transformou seletivamente o espaço intraurbano em termos de acesso a serviços e infraestrutura, configurando o espaço urbano como um local importante na luta entre classes (GUIMARÃES, 2015 e VILLAÇA, 2001). Diante disso entendese que as características do espaço construído, sua configuração e contexto, são causadores de problemas, dentre eles a segregação socioespacial.

\section{O espaço urbano é percebido de diferentes maneiras pelos atores}

que participam de sua produção. No modelo de produção capitalista

o espaço tornou-se uma mercadoria diferenciada, com alto grau de

liquidez, propiciando elevados rendimentos àqueles que o possuem.

Contudo, numa sociedade, cujo modelo prima pela diferenciação, nem

todos podem usufruir do espaço de maneira igual. (MUSSATO. 2011. p. 7)

Por muito tempo a rua, tida como uma extensão das residências, porém de caráter público, possibilitou o encontro entre pessoas, gerando diferentes formas de interação, tanto social, quanto cultural. Com a inserção do automóvel, no século XX, dificuldades como distância deixaram de ser um problema, o que aumentou de certa forma, a dependência dos automóveis, privilegiando o fluxo veicular e não mais de pedestres. Com isso, os espaços públicos e afins acabaram sendo cedidos, tendo em conta a necessidade de construção de vias maiores que comportassem o fluxo cada vez mais intenso de veículos. Como consequência, as ruas tornaram-se mais perigosas para caminhar, aumentando a violência e reduzindo a largura das calçadas tornando-as menos atrativas e seguras. Tudo isso com um altíssimo custo de investimentos voltados ao veículo motorizado e pensando pouco em estratégias de produzir cidades mais atrativas às pessoas.
Contextualizado pelas suas poucas inserções, segundo Montenegro (2005), o mobiliário urbano vem adquirindo papel desempenhado no contexto das cidades modernas, papel desempera urbana, com o emprego de técnicas e materiais que materiais que induzem sua utilização.

O mobiliário urbano de cada cidade deve constituir uma singularidade, uma identidade. A função desses objetos deve ser entendida e a estética percebida de forma a deve ser entendida e a estética percebida de forma a de alguma maneira se usuario. A forma do objeto deve de alguma maneira se integrar no contexto urbano e ao LINDEN, 2010. p. 6).

Nesse sentido, Serra (2002) reitera alguns propósitos acerca de tais elementos na cidade:

Os elementos de mobiliário e microarquitetura urbanos se instalam no espaço público com o propósito comum de oferecer um serviço ao cidadão; um serviço que tem usos e funções muito diferentes já que estas vão surgindo conforme aparecem novas necessidades na cidade; a comunicação, o lazer, o descanso, a manutenção, a limpeza, a limitação e o ordenamento de espaços de pedestres e veículos. (SERRA, 2002. p.18).

Ao longo da história, conforme Tessarine (2008), os elementos entendidos como mobiliário urbano começaram a atrair a atenção das entidades responsáveis pelos espaços públicos, as quais passaram a criar regras a fim de decidir a localização e implantação dos mesmos, dada a importância destes objetos em meio à cidade.

Ainda acerca da relevância do mobiliário urbano Lamas (2000) reitera que o mesmo é essencial para o desenho e 
Ainda acerca da relevância da inserção de tais elementos Montenegro (2005), reforça:

O desenvolvimento desses objetos urbanos adquire

um grau de importância dentro dos projetos de

intervenção urbanística dos espaços urbanos

públicos na medida em que representam um fator

de valorização no uso do espaço público, através da

prestaç̃o de servicos, atendimento de necessidades

desempenho de funções específicas. (MONTENEGRO, 2005. p. 31-32).

Em suma, entende-se que os mobiliários urbanos quando associados ao uso do espaço "facilitam convivência social e 0 intercâmbio de experiências individuais e coletivas" (MONTENEGRO, 2005, p.43).

A partir do momento em que se entende o conceito de mobiliário urbano e sua devida função, estende-se também a compreensão acerca da diversidade existente e o que cada objeto representa. Assim sendo, o mobiliário enquanto elemento qualificador e identificador do espaço, torna-se imprescindível no meio urbano, em especial para áreas de lazer e convivio.

Metodologia

A presente pesquisa é de caráter exploratório, iniciada por pesquisa bibliografica a fim de aprofundar o aporte teórico a respeito dos assuntos correlatos ao meio urbano residual e de convivio nas cidades, o que possibilitou maior entendimento de questões referentes a configuração socioespacial existente na macro area de estudo.

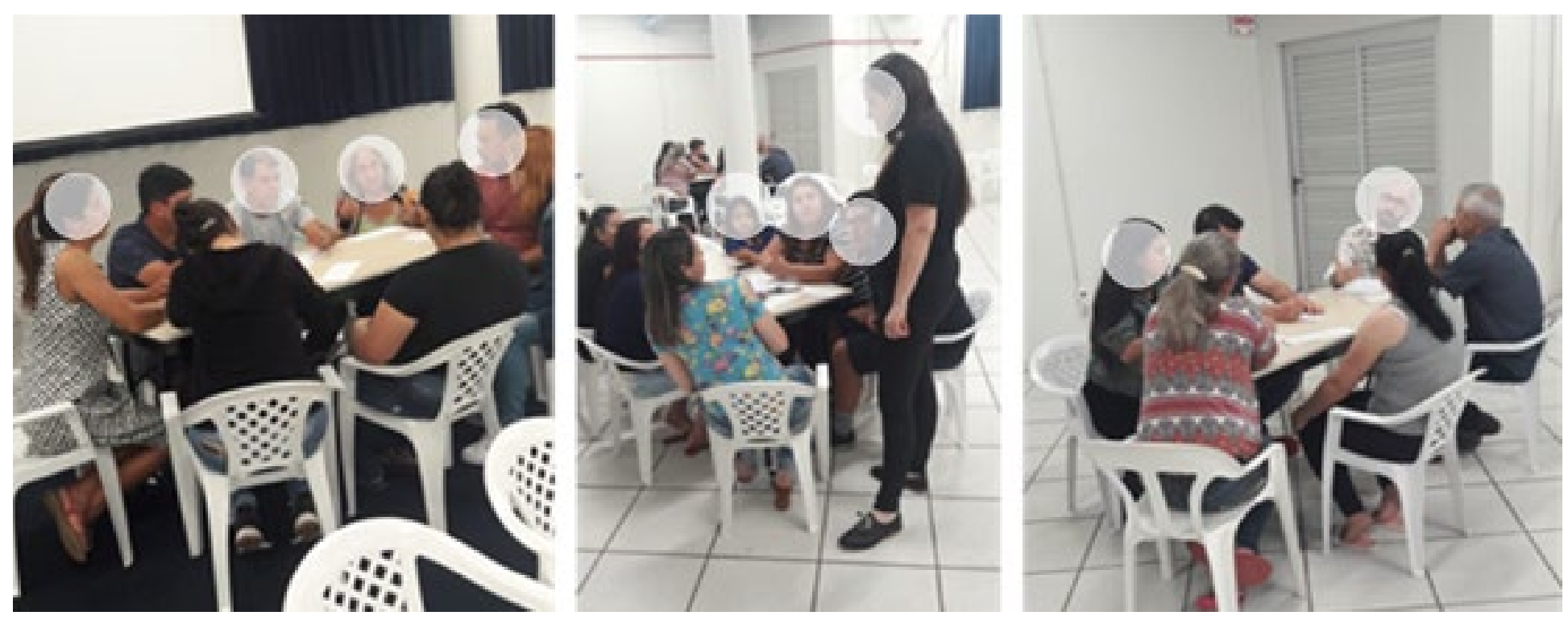

Figura 2: Momento de reflexão entre grupos, para elaboração de propostas futuras

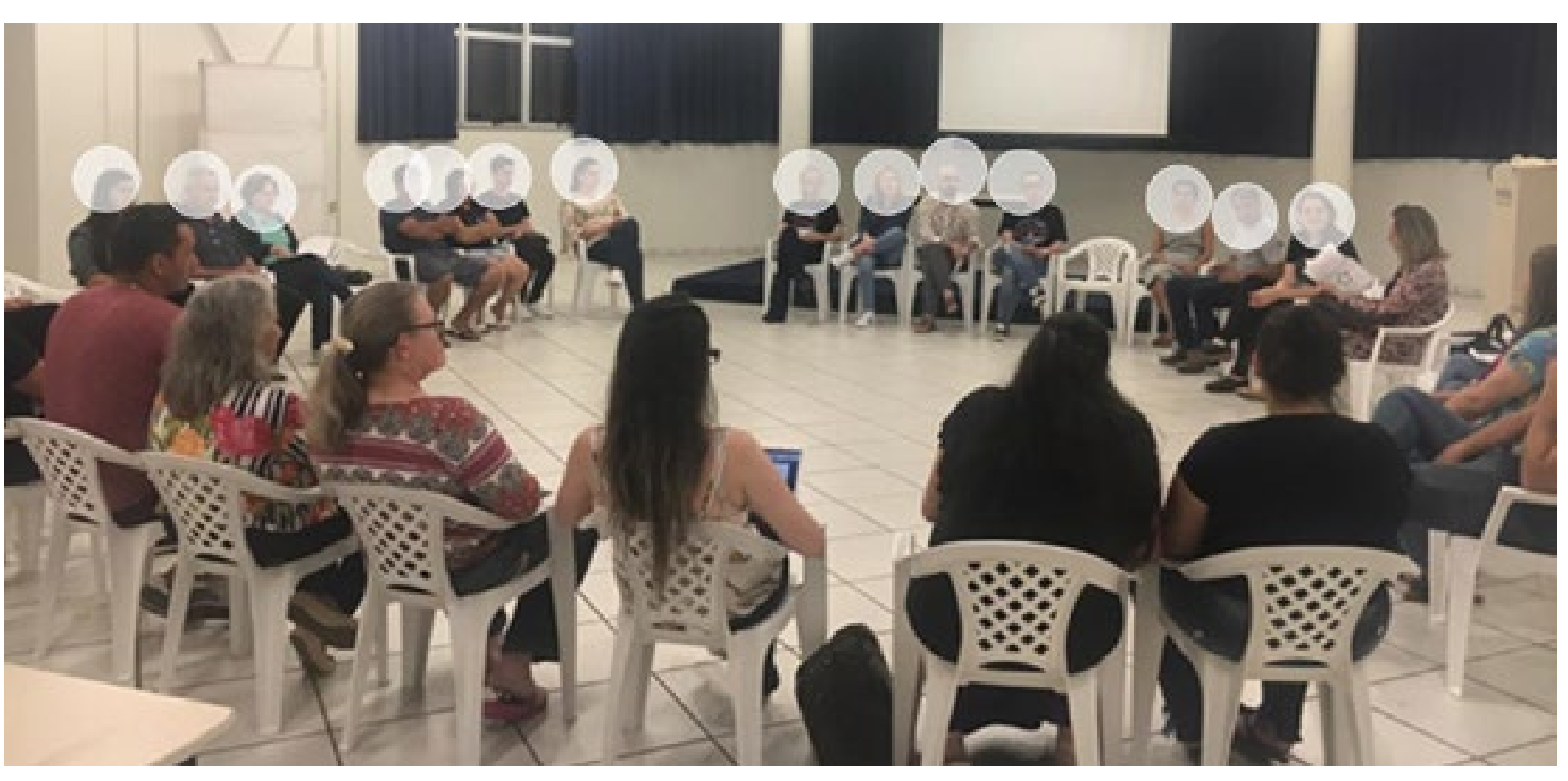

Figura 3: Momento de compartilhamento das ideias entre a comunidade 


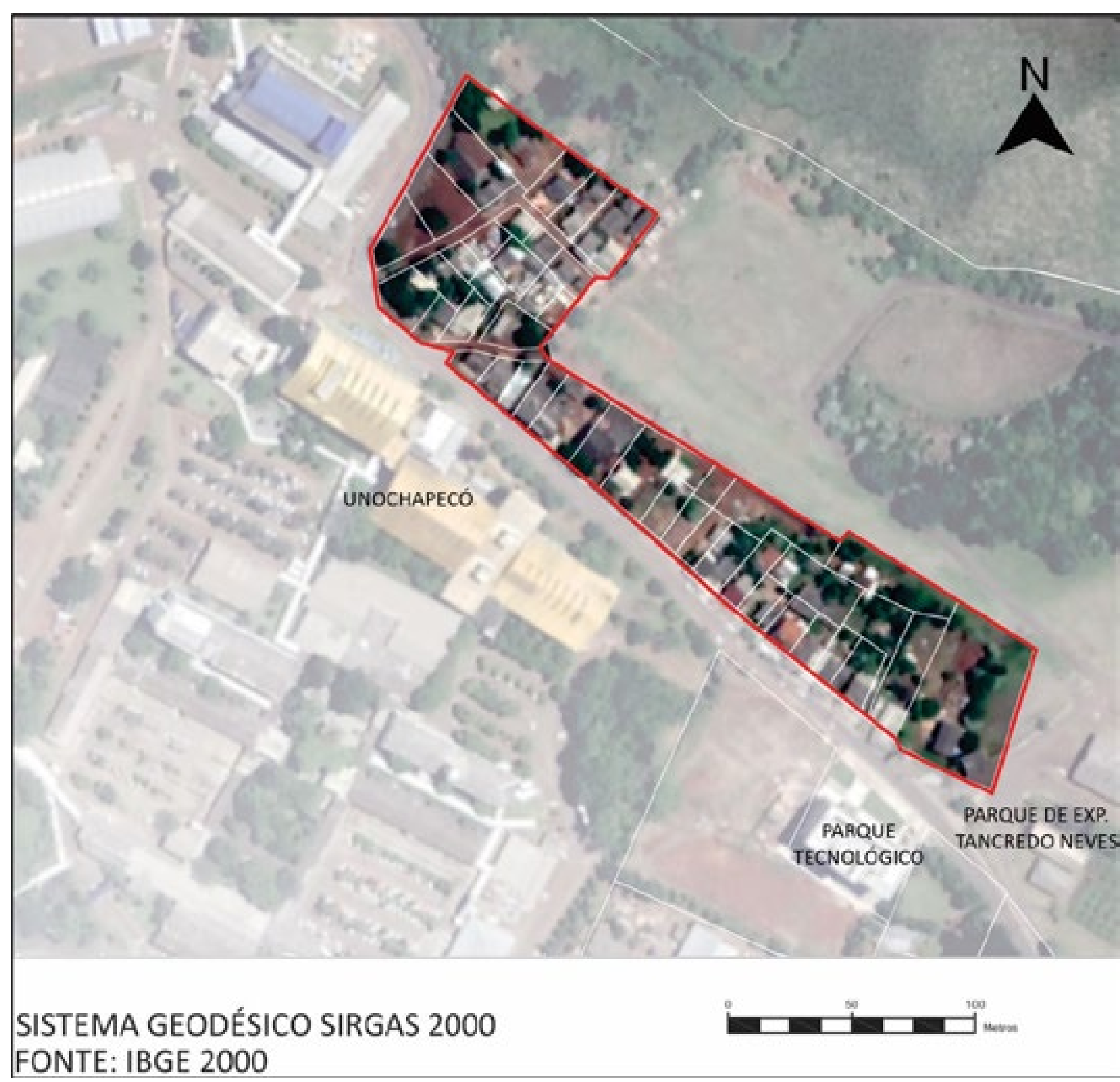

Posteriormente delimitou-se a área de estudo, para que, em seguida fosse possível realizar uma abordagem mais profunda com os moradores, de modo a garantir maior entendimento acerca da problemática. Para tal, realizouse reuniões com os moradores do loteamento (Figuras $02 \mathrm{e}$ de refletir e expor seus incômodos enquanto cidadãos: por meio de conversas e dinâmicas constatou-se vários por meio de conversas e dinâmicas constatou-se vários espaços públicos e de lazer nos arredores do loteamento.

Por fim, tendo conhecimento da problemática e buscando compreender o entendimento dos moradores em relação aos espaços públicos aplicou-se um questionário, online, o qual abordou questões mais espećficicas de modo a possibilitar maior compreensão acerca das tipologias de mobiliários urbanos que possuem maior aceitação por sua parte.

Apresentação da área

Chapecó, a exemplo de várias cidades médias, apresenta diversas áreas segregadas e ocupadas de forma irregular, que consequentemente por não serem projetadas também não possuem áreas de usos coletivos, sendo criadas em seus espaços residuais pela simples ocupação dos moradores, mas sem estruturas, ou simplesmente não existentes. Exemplo disso é o loteamento Unochapecó (Figura 04), ladeado pela Universidade que dá seu nome. Este loteamento, regularizado em 2012, estruturou-se em face a via que conecta uma das entradas principais da Universidade. Ocupando todos os espaços residuais, é visível a formação de um desenho urbano que não possibilita áreas de convívio estruturadas e seguras para seus moradores, que, visando esta necessidade, utilizam espaços além de seus recuos (quase inexistentes), fazendo valer da propria via para convivio e lazer. 


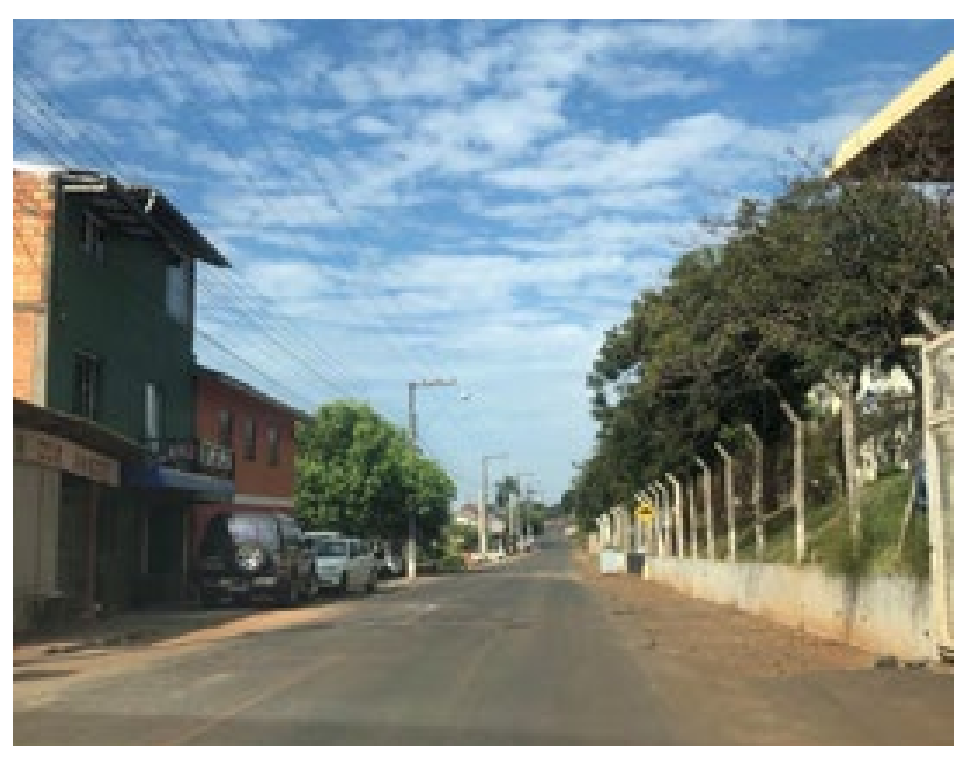

Figura 5: Vista da Rua Eduardo Pedroso da Silva, onde percebe-se a ausência

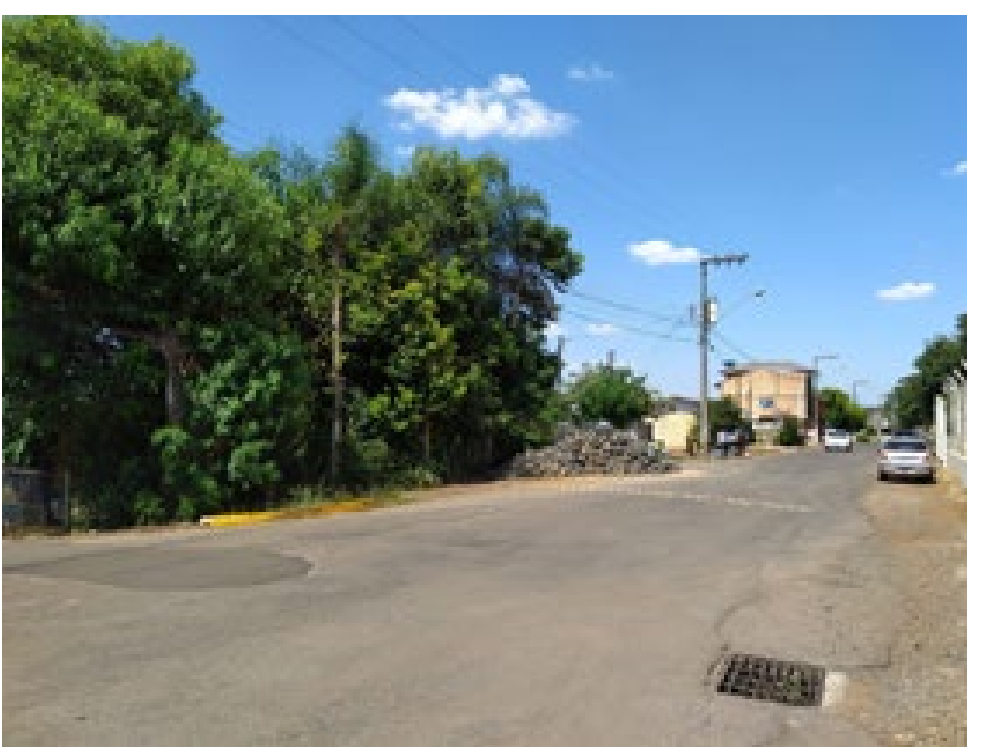

Figura 6: Rua Eduardo Pedroso da Silva, com destaque para a ausência de calca-a-
das, o que torna o espaço impróprio para a realizaçăo de brincadeiras e perigoso das, o que torn
aos moradores

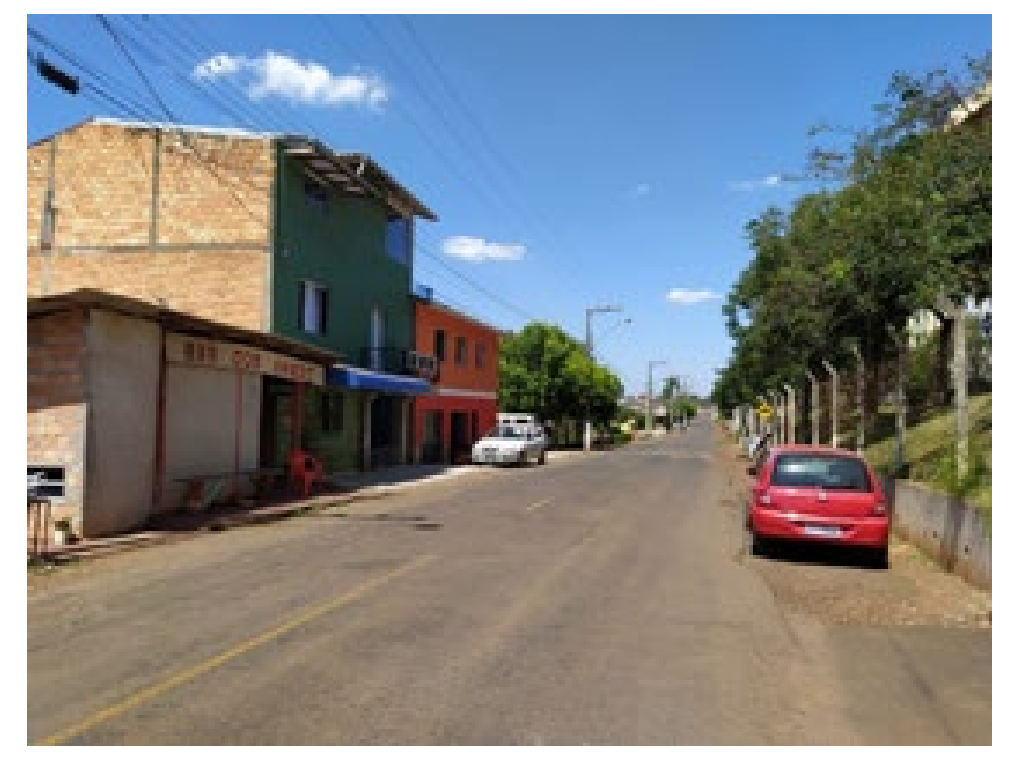

Figura 7: Rua Eduardo Pedroso da Silva, com destaque para a via, cuja configu-

Como já colocado, tendo como base os levantamentos anteriormente realizados, bem como os relatos recebidos em encontros, pode-se constatar que entre as várias inquietações dos moradores encontra-se a carência de espaços de lazer, principalmente no que se refere ao público infantil, haja vista que os mesmos utilizam avia para este fim. Tendo em vista o grande fluxo veicular existente nesta via em função de sua configuração de via coletora devido à presença da Universidade nas proximidades e seu perfil estreito (Figura 05) é notório que a mesma se torna perigosa para tal uso, o que reforça a necessidade de um espaço adequado para tal.

Próximo à área, além da universidade, encontra-se ainda - Parque de Exposiç̃oses Tancredo Neves, mais conhecido como Parque da EFAPI, o qual possui um grande potencial de convivio e lazer, contudo, sua estruturação é dada para acontecimentos de feiras e eventos de maior porte, e o uso diário destina-se ao público da terceira idade, em uma pequena parte do parque, não agregando uso específico às demais faixas etárias.
Nas reuniões com os moradores, a carência de espaços de lazer para as crianças foi apresentada com maior ênfase, no entanto o que se vê no dia a dia é que todos os moradores, independente de idade, carecem de um espaço adequado. Dessa forma, buscou-se trabalhar com tipologias que venham a sanar as necessidades de ambos, prezando por um espaço onde a convivência possa ocorrer de forma saudável. Diante disso, tendo consciência da importância da inserção destes espaços, realizou-se uma consulta aos moradores com o intuito de lhes apresentar ideias e possíveis tipologias que podem beneficiar não somente o público infantil.

Desde os primeiros anos de vida as pessoas necessitam umas das outras para viver bem, pois a convivência é responsavel pela socializaçao dos seres humanos e está presente em suas relaçoes interpessoais. A necessidade de convivio em grupo, principalmente na infância, e de relacionar-se com outros individuos e uma característica inerente e de suma importância para o desenvolvimento do ser humano levando em consideração os benefícios a 


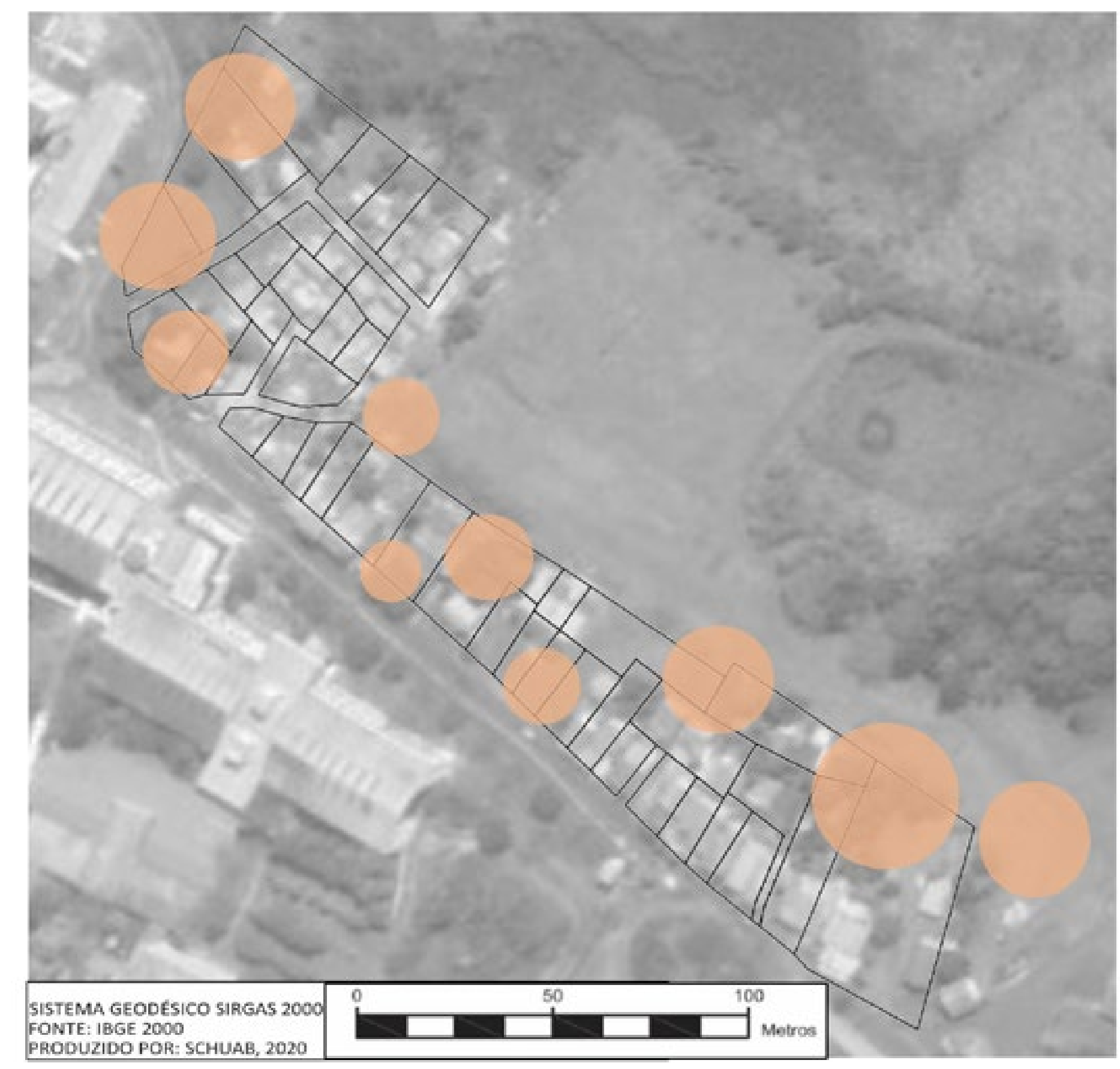

ela relacionados, como o bem-estar físico e psicológico. Além disso, sabe-se que estar em companhia de outras conflitos, a partir da potencialização de oportunidades de ampliação de horizontes, auxiliando no crescimento pessoal.

A distribuição desigual dos espaços públicos, espaços

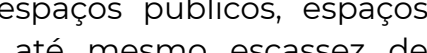
precarios, falta de atividades familires gratuitas são fatores que afetam atividades familiares gram una cidatos que afetam a desigualdade social em uma cidade. Aspectos como a interagindo com o espaço urbano dizem muito sobre uma cidade, haja vista que demonstra a quão preocupada ela está com as novas gerações e qual a qualidade de vida que está oferecendo aos cidadãos. No caso do Loteamento Unochapecó, como é possível reforçar a partir das figuras 07 e 08, não há condições da população sentir-se segura com as crianças brinçando nas ruas e espaços residuais, visto que eles são prioridades dos veículos e não possuem condições de lazer.

Desse modo, tendo conhecimento das diferentes vantagens atribuídas à convivência, bem como as vivências e experiências adquiridas por meio dessa interação é que se busca explorar a criatividade de modo a oferecer à comunidade, principalmente ao público infantil, um espaço capaz de auxiliar nesse processo. 
Tem-se conhecimento que grande parte da população possui uma jornada de trabalho de pelo menos 8 horas diárias, sendo esta, em sua maioria constituída por famílias formadas por cônjuges e filhos. Sabe-se que a maior parte das escolas não oferecem seus serviços em turno integral, com isso as crianças só podem frequentar a escola em de um espaço a Nequado para que estas crianças possam permanecer no contra turno escolar.

A Constituição Brasileira de 1988, o Estatuto da Criança e do Adolescente de 1990 e a Convenção sobre os Direitos da Criança de 1999 adotada pela Assembleia das Nações Unidas, são importantes conquistas que tornam o ato de brincar indispensável para o desenvolvimento social, físico e cognitivo da criança.

É nos primeiros anos de vida que as crianças aprendem a brincar e por meio disso passam a entender que ambiente onde se encontram os proporciona segurança desse modo, criam vínculos afetivos e relações sociais com os demais indivíduos que as circundam.

Diante disso, entende-se que os espaços livres urbanos são extremamente relevantes, representando vital importância tanto funcional quanto ambiental, cultural e social.

Nesse sentido, torna-se essencial ainda, que os brinquedos e brincadeiras desenvolvidos, independente de faixa etária ou nível cultural e econômico, devam ser planejados com base em critérios que proporcionem o máximo possível de segurança e tranquilidade nos momentos de lazer.

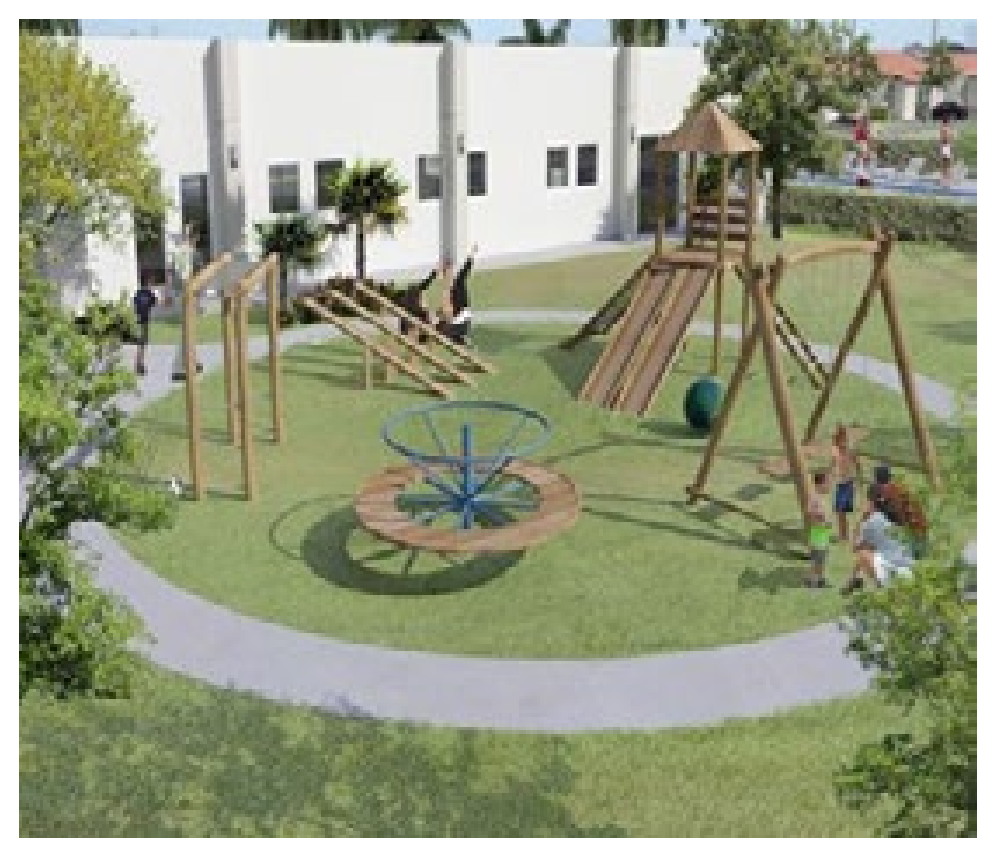

Figura 9: Mobil
questionário.

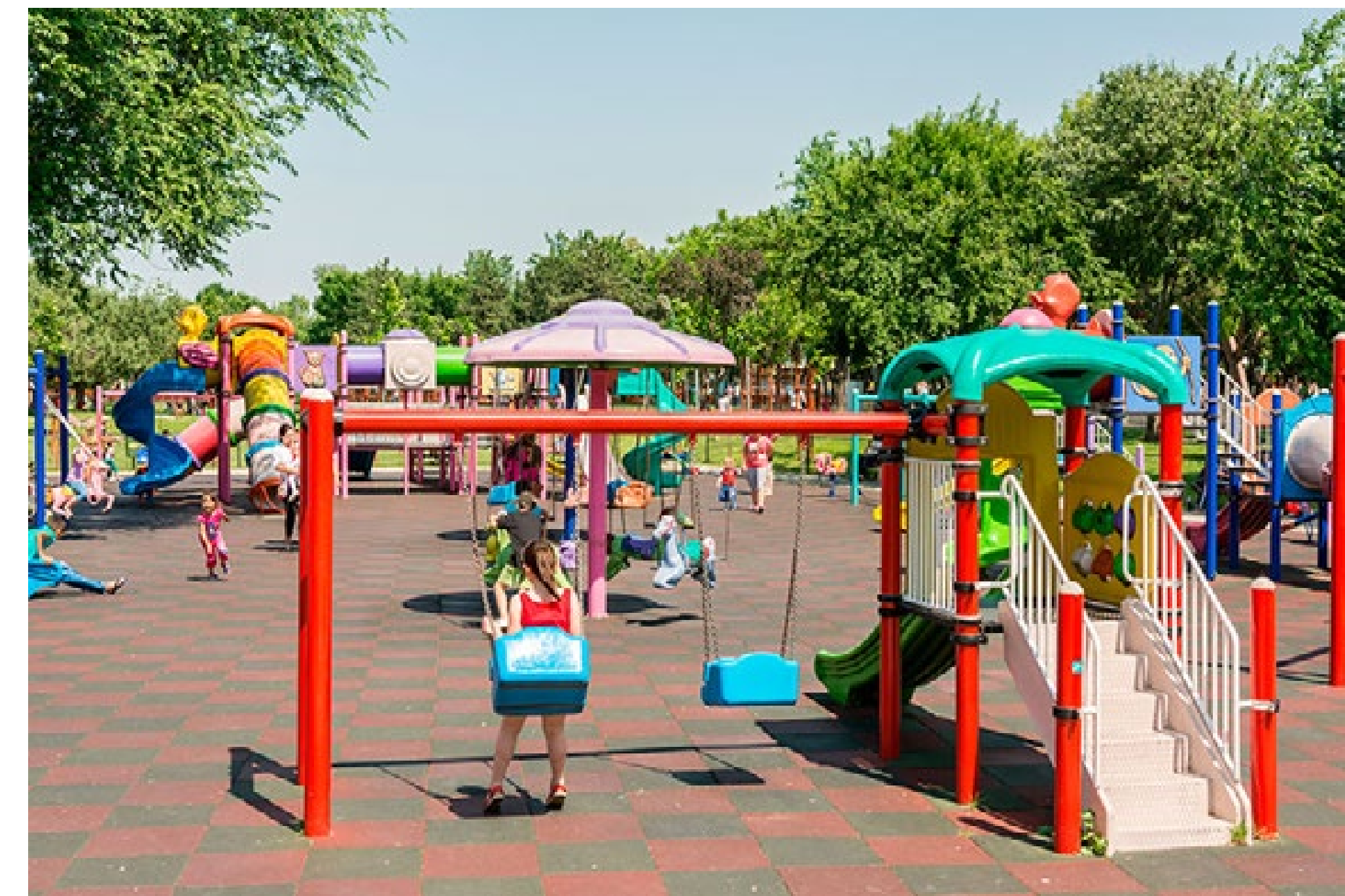

Figura 10: Mobiliário com playgrounds tradicionais utilizados como exemplo no questionário.

O lazer é o conjunto de ocupações às quais o indivíduo seja para divertir-se, recrear-se e entreter-se ou ainda desenvolver sua formaçâo desinteressada, sua participação social voluntaria, ou sua livre capacidade criadora, após livrar-se das obrigações profissionais, familiares e sociais. (DUMAZEDIER, 1976) 


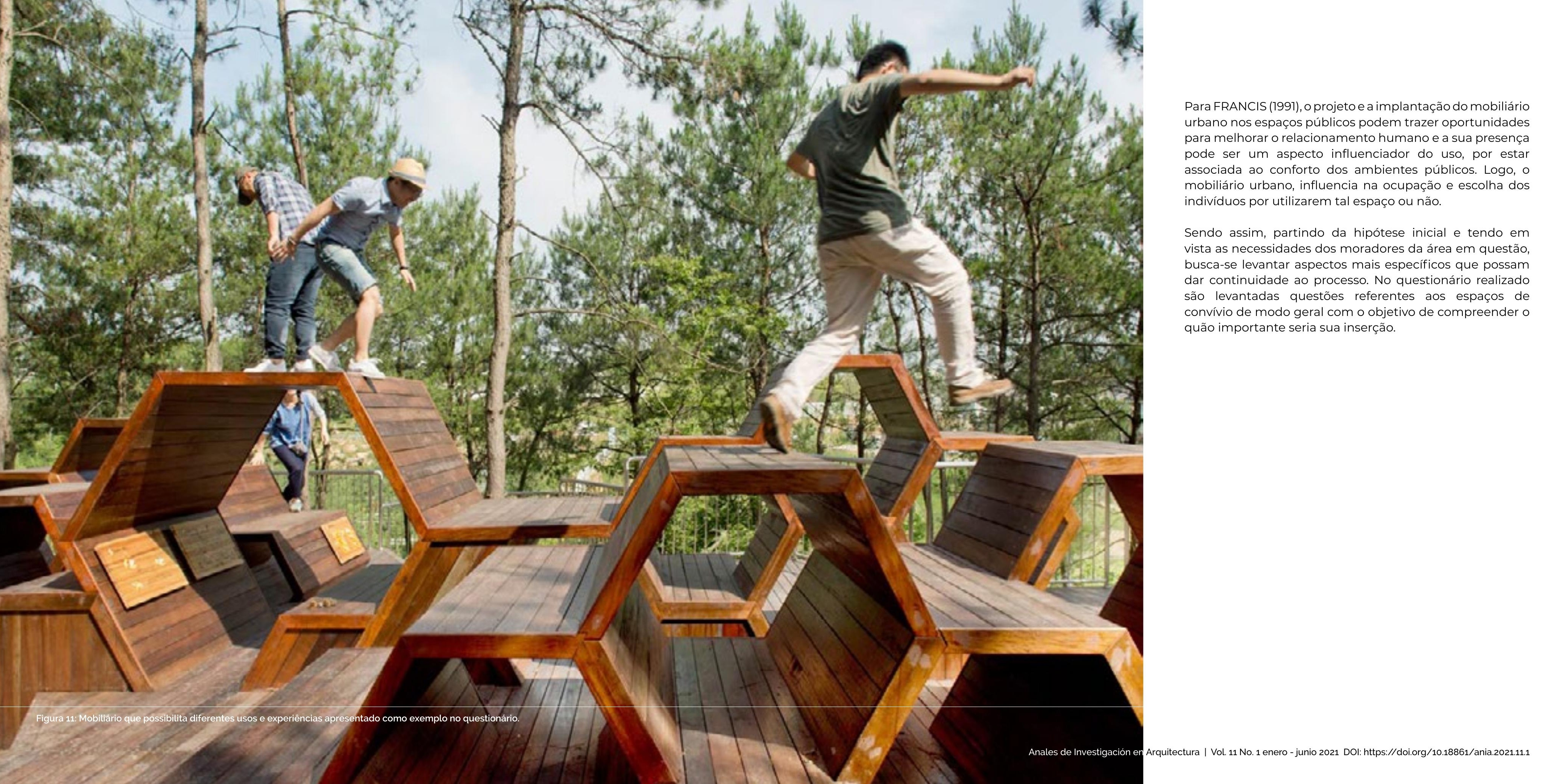




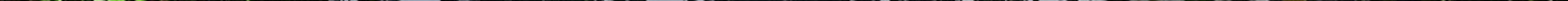


Tendo consciência da importância da inserção de um novo espaço de lazer na área de estudo, identificou-se algumas áreas passíveis de inserção de mobiliários urbanos para usos de convívio, conforme apresenta a Figura 08. Identificouse alguns resquícios de lotes e poucas áreas verdes no que já está consolidado e regularizado como lote. Porém esta área faz divisa com outras áreas públicas municipais e da Universidade que poderiam ser constituídas como áreas públicas de lazer, trazendo a inserção dos mobiliários moradores do Loteamento Unochapecó. Concomitantemente com este levantamento, realizou-se
uma consulta aos moradores por meio de questionário online (devido a ocorrência da Pandemia de covID-19 no decorrer da pesquisa), com o intuito de lhes apresenta ideias e possíveis tipologias, as quais iriam beneficiar não somente o público infantil.

Entende-se que um bom espaço de convívio é aquele que estimula a convivência entre os indivíduos e que cria condições de permanência, que convidam as pessoas a permanecer nestes locais. Nesse sentido, pôde-se constatar que $100 \%$ dos entrevistados concordaram que estes espaços de convívio são importantes e que sejam compartilhados por diferentes faixas etárias, o que possibilita maior interação e troca de experiências.

Conforme citado anteriormente, a carência de espaços adequados para lazer existe, situação esta, que ficou reforçada no questionário, no qual as famílias que possuem crianças afirmam que $44 \%$ das mesmas brincam no interior de suas residências ou até mesmo na rua devido à ausência de um espaço próprio para isso. Além disso, $100 \%$ dos entrevistados afirmaram que usariam espaços de lazer e convívio caso fosse implantado na ár sendo que a maior (56\%) afirmaram que usariam muito.

A distribuição desigual dos espaços públicos, espaços precários, falta de acesso e até mesmo a escassez de precários, falta de acesso e ate mesmo a escassez de desigualdade social em uma cidado nue afetam a mais por ser um loteamento de ocupaça irregusar mesmo que já regularizado.

No discurso dos moradores a carência de espaços de lazer para as crianças já era claro, corroborando como fato que é visível o uso dos espaços residuais pelos adultos no dia a dia e reforça o fato da necessidade destes espaços não só para crianças, mas para jovens, adultos e idosos, que ficam em grande parte sentados à beira da via, tomando mate ou simplesmente usando um tempo de lazer com os vizinhos. Dessa forma, buscou-se trabalhar com tipologias que viessem a sanar as necessidades de ambos, prezando por um espaço onde a convivência possa ocorrer de forma saudável.

Sendo assim, questionou-se também o fato de que eles poderiam fazer uso de outros tipos de mobiliários, cujas tipologias não fossem restritas somente à uma faixa etária. Nesse sentido, quando comparados aos mobiliários tradicionais (Figuras 09 e 10), os mobiliários com formas e tipologias diferenciadas os atraíram mais (Figuras $11 \mathrm{e}$ 12). Dessa forma, a inserção de elementos diferenciados traria uma identidade específica desse local, fugindo dos padrões até então existentes nos arredores.

Partindo do pressuposto, entende-se que a inserção de espaços mais ludicos e que permitem a criança explorar
- local tiveram destaque. Fazendo, assim, com que cada erento, cor ou forma do local permita uma nova descoberta, trazendo à tona experiências diferenciadas.

Vale ressaltar que os brinquedos e brincadeiras desenvolvidos, independentedefaixa etária ounívelcultural desenvolvidos, independente defaixa etária ou nível cultural que proporcionem o máximo possivel de segurança tranquilidade nos momentos de lazer. Por fim entendese que a presença de espaços livres urbanos é relevante, carregando consigo importância tanto funcional e formal, quanto ambiental e social. Assim, sua inserção iria além de apenas uma referência física, se tornando também um ponto de troca de experiências.

Dessa forma, levando em consideração os aspectos apresentados, fica reforçada a importância de espaços de convivio em meio a cidade, bem como os inúmeros benefícios a eles atrelados, e em especial em áreas que nasceram irregulares. Assim sendo, pode-se dizer que os dados coletados por meio da presente pesquisa mostramse condizentes quando comparados às bibliografias estudadas. Nesse sentido, tornou-se visível o entendimento da comunidade acerca da necessidade de um espaço de convívio de qualidade, bem como a importância dos mesmos. Sugere-se, no entanto, continuidade à pesquisa para aprofundar análises comportamentais desses moradores e posteriormente definir um projeto de espaço adequado e capaz de atender a demanda e necessidades dessa gleba.

\section{Notas finales:}

Aprobacion final del artículo: editora en jefe Arq. Carla

Nóbile.

Contribución de autoría:la elaboración del artículo es obra única de los autores. 
ARANTES, O. (1995) A ideologia do "lugar público" na arquitetura contemporânea. In: ARANTES, O. O lugar da arquitetura depois dos modernos. 2. ed. São Paulo: EDUSP.

BALBI, T. M. (2017) A vida, a morte e aquilo que sobra: os espaços residuais como elementos de uma ecologia comunicacional dos lugares da cidade. 2017. 147p. Tese (Doutorado em Comunicação e Semiótica) - Programa de Estudos Pós-Graduados em Comunicação Semiótica, Pontifícia Universidade Católica de São Paulo, São Paulo.

BASSO, L. VAN DER LINDEN, J. (2010) Mobiliário urbano: origem, forma e função. In: $9^{\circ}$ CONGRESSO BRASILEIRO DE PESQUISA EM DESIGN, São Paulo, SP.

CARACAS,L.B.(2002)Espaçoslivrespúblicos:dimensãosimbólicaeidentidade.In:ENCONTRO NACIONAL DE ENSINO DE PAISAGISMO EM ESCOLAS DEARQUITETURA E URBANISMO,6, 2002, Recife. Anais da construção da Paisagem Brasileira. Recife: Laboratório de Paisagem/ UFPE, 2002.

DUMAZEDIER, J. (1994) Sociologia Empírica do Lazer. São Paulo: Perspectiva. 2 ed.

FERRARA, L. D. (2000) Os significados urbanos. São Paulo: Edusp/Fapesp,192 p.

FRANCIS, M. (1991) Urban Open Spaces. In: ZUBE, E., MOORE, G. (orgs.). Advances in Environment, Behavior and Design, vol. 1, p.71-106.

FUJITA, C. (2008) Dilema urbano-ambiental na formação do território brasileiro: desafios ao planejamento urbano no Brasil. Tese (Doutorado - Area de Concentração: Paisagem e Ambiente) - FAUUSP, São Paulo, 2008

GUIMARÃES, M. C. R. (2015) Os movimentos sociais e a luta pelo direito à cidade no Brasil contemporâneo. Serviço Social \& Sociedade, São Paulo, n. 124, p. 721-45, out./dez.

LAMAS, J. M. R. G. (2000) Morfologia Urbana e Desenho da Cidade. Lisboa: Fundação Calouste Gulberkian. p.108.

MONTENEGRO, G. (2005) A produção do mobiliário urbano em espaços públicos: o desenho do mobiliário urbano nos projetos de reordenamento das orlas do RN. Dissertação (Mestrado em Arquitetura e Urbanismo, Universidade Federal do Rio Grande do Norte, Natal, 2005). Disponível em: http://bdtd.ibict.br/. Acessado em 27 abr. 2020
MUSSATO, O. B. (2011) Urbanização e segregação socioespacial: uma análise do caso Monte das Oliveiras em Boa Vista - RR. 2011. 118 f. Dissertação (Mestrado) - Curso de Economia, Universidade Federal do Rio Grande do Sul, Porto Alegre.

RECHE, D. (2008) A influência do capital agroindustrial na distribuição sócio-espacial urbana do município de Chapecó no sul do Brasil. X Colóquio Internacional de Geocrítica. Barcelona, Universidad de Barcelona. Disponível em http://www.ub.edu/geocrit/-xcol/257. html. Acessado em 04 de junho de 2020.

SILVA, M. M.NETO DAET AL. (2016) Segregaçãosocioespacial: Os impactos das desigualdades sociais frente a formação e ocupação do espaço urbano. Revista Monografias Ambientais, Santa Maria, v. 15, n. 1, p. 256-263.

SERRA, J.M M. (2002) Elementos Urbanos: mobiliário e microarquitetura. Barcelona: Gustavo Gili. p.18.

TESSARINE, J. B. (2008) O Mobiliário Urbano e a Calçada. Dissertação (mestrado). Programa de Pós-Graduação Strictu Sensu em Arquitetura e Urbanismo. Universidade São Judas Tadeu. São Paulo, SP, $116 p$.

VIVAN, M., \& SABOYA, R. (2012). Arquitetura, espaço urbano e criminalidade: relaçōes entre espaço construído e segurança, com foco na visibilidade. II Encontro da Associação Nacional de Pesquisa e Pos-graduaça en Arquitetura e Unbanismo, Enaparq, Natal, Rio Grande do Norte, Brasil. p. 1-20. Disponivel em: https:/Www.researchgate.net/ publication/235436772_Arquitetura_espaco_urbano_e_criminalidade_relacoes_entre_ espaco_construido_e_seguranca_com_foco_na_visibilidade. Acessado em 17 mar. 2020.

YANG, P. (2013). Entre, São Paulo. Disponível em http://entre-entre.com/? Entrevistald=19. Acessado em 10 mar. 2027
Figura 01: Siste
Schuab (2021)

Figura 02: Schuab, 2019

Figura 03: Schuab, 2019

Figura 04: Google Maps. Editado por Schuab (2020).

Figura 05: Schuab, 2020

Figura 06: Schuab, 2020

Figura 07: Schuab, 2020

Figura 08: Sistemas Geodésicos Sirgas (2000). Editado por Schuab (2027).

Figura 09:GaúchaZH,2020.Disponivelem:https:/gauchazh. clicrbs.com.br/porto-alegre/noticia/2020/02/novoplayground-e-inaugurado-na-redencao-em-portoalegre-ck6mj529x0j9901qdo40ls62s.html. Acessado em 15 de fevereiro de 2021.

Figura 10: Dreams Time. Disponivel em https://www. dicasdajapa.com.br/5-atividades-educativas-para-seufilho/. Acessado em 15 de fevereiro de 2021.

Figura 11: Landezine, 2017. Disponivel em http://landezine. $\mathrm{com} /$. Acessado em 15 de fevereiro de 2021.

Figura 12:ArchDaily Brasil, 2012. Disponível em: https://www. archdaily.com.br/br/624244/praca-infantil-iguatemistudiomk27-marcio-kogan-mais-eduardo-gurian-maismarcio-tanaka. Acessado em 15 de fevereiro de 2027. 